\title{
Diethylstilbestrol decreased adrenal cholesterol and corticosterone in rats
}

\author{
Satoko Haeno', Naoyuki Maeda',5, Takeshi Yagi', Sachi Tahata', Michiko Sato', \\ Kanako Sakaguchi ${ }^{2}$, Taku Miyasho ${ }^{4}$, Hiromi Ueda ${ }^{3}$ and Hiroshi Yokota' \\ ${ }^{1}$ Laboratory of Veterinary Biochemistry, ${ }^{2}$ Laboratory of Veterinary Pathology, ${ }^{3}$ Laboratory of Veterinary Anatomy, \\ School of Veterinary Medicine and ${ }^{4}$ Laboratory Animal Nutrition, School of Veterinary Science, Rakuno Gakuen \\ University, Ebetsu, Hokkaido 069-8501, Japan \\ ${ }^{5}$ Japan Meat Science and Technology Institute, Ebisu, Shibuya-ku, Tokyo 150-0013, Japan
}

\author{
Correspondence \\ should be addressed \\ to $\mathrm{H}$ Yokota \\ Email \\ h-yokota@rakuno.ac.jp
}

\begin{abstract}
The synthetic oestrogen diethylstilbestrol (DES), which is known to bind oestrogen receptors (ERs), has been reported to have adverse effects on endocrine homeostasis; however, the molecular mechanisms underlying these effects are poorly understood. In this study, we treated rats with DES and found high levels of this compound in the liver, adrenal glands and pituitary gland, as compared with other tissues. We have also detected early adverse effects of DES in the adrenal glands. The adrenal glands of rats treated with DES $(340 \mu \mathrm{g} / \mathrm{kg}$ body weight every 2 days) for 2 weeks showed increased weight and size and a decreased fat droplet size. Following 1 week of treatment with DES, the blood and adrenal corticosterone levels were substantially decreased without any histological alterations. The levels of the precursors for corticosteroid biosynthesis in the adrenal glands were also decreased, as determined using mass spectroscopy. Cholesterol, the principal material of corticosteroid biosynthesis, decreased substantially in the adrenal glands after only 1 week of treatment with DES. In conclusion, cholesterol insufficiency results in a reduction in adrenal corticosterone biosynthesis, which may lead to endocrine dysfunction, such as reproductive toxicity.
\end{abstract}

\section{Key Words}

- diethylstilbestrol

- endocrine disruptor

- corticosterone

- adrenal insufficiency

- cholesterol

\section{Introduction}

Concerns have been raised regarding human health and the potential adverse effects of environmental chemicals, such as endocrine disruptors, which mimic the effects of oestrogen in reproduction and development. Endocrine disruptors are known to exert reproductive toxicity via a non-genomic oestrogen receptor (ER)-initiated pathway (Wong \& Cheng 2011), although there is increasing evidence that environmental toxins can affect the reproductive system via multiple pathways and various mechanisms (Watson et al. 2011). One of the most well-studied endocrine disruptors, diethylstilbestrol (DES), is a synthetic non-steroidal oestrogen that was used in the USA and Europe from the mid-1940s to the 1970s for the prevention of spontaneous abortion and premature delivery. The offspring of these types of pregnancies have been shown to be at risk for numerous medical conditions, including vaginal adenocarcinoma and malformation of the testes (Schrager \& Potter 2004, Newbold et al. 2006, Martin et al. 2008, Palmer et al. 2009, Shin et al. 2009, Unüvar \& Büyükgebiz 2012). In one large

Published by Bioscientifica Ltd 
cohort, the median total dose of DES administered to pregnant mothers ranged from 1625 to $10424 \mathrm{mg}$ ( $\sim 23 \mathrm{mg}$ to $150 \mathrm{mg} / \mathrm{kg}$ of body weight; Giusti et al. 1995). Although the detailed mechanism of DES action and its pharmacokinetics are not well understood, DES has been shown to bind to the ERs (Korach \& McLachlan 1985, Kuiper et al. 1997, Henley \& Korach 2006). While DES is no longer used clinically for the prevention of miscarriage, it remains a useful compound for investigating the mechanism of action of exogenous oestrogens (Kaludjerovic \& Ward 2012). DES has been extensively used as a treatment for prostate cancer in humans. Higher doses of DES-diphosphate $(500-1000 \mathrm{mg} /$ day for $2-5$ weeks) were found to suppress the serum level of testosterone for the treatment of prostate cancer patients (Kitahara et al. 1999). DES, a synthetic non-steroidal oestrogen, binds to ERs and exhibits strong oestrogenic toxicities, including adverse reproductive effects on male animals (Hillered \& Ernster 1983, Dean et al. 1997). It is now accepted that oestrogens play a role in male fertility and that exposure to exogenous oestrogens during foetal and neonatal life can lead to reproductive disorders in males. However, the ER-mediated processes involved in the regulation of male reproduction during foetal and neonatal development remain largely unclear. It is also important to keep the reproductive organs of adult men and male animals healthy by preventing adverse effects from environmental pollutants and chemicals that also possess oestrogenic activity. Further investigation of the detailed molecular mechanisms of the deleterious effects on adult males is necessary. It is important to identify the initial targets and the early adverse effects of DES by following reproductive abnormalities in adult males. Results of the DES studies are currently being used to better characterise the biological effects of other oestrogenic compounds (Kaludjerovic \& Ward 2012). Owing to the complexity of the processes involving DES, it is difficult to determine the molecular mechanism until a specific toxic effect is observed. As described in Kaludjerovic \& Ward (2012), it would be valuable to elucidate the mechanism and to identify the multiple pathways involved in DES toxicity. The triggers that elicit the aforementioned toxic effects have yet to be identified.

Endocrine-disrupting chemicals, including polychlorinated biphenyls, dioxin, lindab and others, can affect the synthesis of adrenal steroids; however, only a few studies investigating their effects on the adrenal glands and adrenal steroidogenesis have been carried out, and no studies of the adrenal P450s, which are involved in corticosterone biosynthesis, have been reported (Diamanti-Kandarakis et al. 2009). Zimmerman et al. (1991) is the only research paper to report an increase in adrenal weight and decrease in steroid hormone levels. Corticosterone, which is the principal glucocorticoid in rodents and is synthesised in the zona fasciculata (ZF), regulates metabolism, the stress response and immune function. In addition, adrenal steroids play important roles in foetal development and delivery (Chida et al. 2011, Huang et al. 2012). Therefore, the objective of this study is to investigate the interactions between endocrine disruptors and adrenal corticosterone synthesis suppression.

In this study, we directly demonstrated the tissue distribution of DES and found that the adverse effects of DES involve corticosteroid biosynthesis in the adrenal glands as an initial step of its mechanism of toxicity, which may lead to the disruption of various biosynthetic pathways.

\section{Materials and methods}

\section{Treatment of animals}

Male Sprague-Dawley rats (weight, $280 \pm 20 \mathrm{~g}$ and age, 8-10 weeks) were fed, housed and allowed to adapt to their environments for 1 week before the experiments. The rats received an oral dose of $0.1 \mathrm{mg}$ of DES dissolved in $1 \mathrm{ml}$ of olive oil ( $\sim 340 \mu \mathrm{g} / \mathrm{kg}$ of body weight) to study the distribution of DES. The same dose $(\sim 340 \mu \mathrm{g} / \mathrm{kg}$ of body weight) was administered every 2 days for a total of four doses over 1 week or eight doses over 2 weeks to study the effects of DES. Control rats received $1 \mathrm{ml}$ of olive oil. Blood was collected from the abdominal aorta of the animals via exsanguination under pentobarbital anaesthesia. After dissection, the organs were excised post-mortem, weighed and then immediately frozen and stored at $-25^{\circ} \mathrm{C}$. All animals were treated according to the Laboratory Animal Control Guidelines of Rakuno Gakuen University, which conform to the Guide for the Care and Use of Laboratory Animals of the National Institutes of Health, USA (NIH 1985).

\section{Morphological analysis}

Rats (three per group) were anesthetised with Nembutal (pentobarbital; Abbott Japan Co., Tokyo, Japan). First Ringer's solution and then a solution of $4 \%$ paraformaldehyde in $0.1 \mathrm{M}$ phosphate buffer $(\mathrm{PB})(\mathrm{pH}$ 7.4) for $10 \mathrm{~min}$ were perfused through the aortae. Following fixation, tissue blocks ( $3 \mathrm{~mm}$ thick) of the adrenal gland were dehydrated in an ascending ethanol series, cleared in

Published by Bioscientifica Ltd. 
xylene and embedded in paraffin wax. The sections were cut to a thickness of $5 \mu \mathrm{m}$ and stained with haematoxylin and eosin (HE) before examination under a light microscope. For analysis by transmission electron microscopy, adrenal glands perfused with $4 \%$ paraformaldehyde were cut into 1-mm cubes and fixed via immersion in $4 \%$ paraformaldehyde and $2.5 \%$ glutaraldehyde in $0.1 \mathrm{M} \mathrm{PB}$ for $2 \mathrm{~h}$. The tissue blocks were rinsed in $0.1 \mathrm{M}$ $\mathrm{PB}$ and post-fixed in $1.0 \%$ osmium tetroxide in $0.1 \mathrm{M} \mathrm{PB}$ for $1 \mathrm{~h}$. After dehydration in a graded ethanol series, the specimens were embedded in Quetol 812 (Nisshin EM, Tokyo, Japan). Ultrathin sections (80-100 nm-thick) were prepared and stained with $2 \%$ methanolic uranyl acetate and $1 \%$ lead citrate and were subsequently observed using a transmission electron microscope (JEM-1220; JEOL, Tokyo, Japan). Cryosections ( $7 \mu \mathrm{m}$-thick) of snap-frozen adrenal glands were prepared on a cryostat microtome (CR-502; Yamamoto Kohki Industrial, Saitama, Japan). The cryosections were routinely stained with haematoxylin for nucleic acid visualisation and Oil Red $\mathrm{O}$ (Sigma) for lipid visualisation.

\section{Preparation of samples and assay method for MS analysis}

The samples were prepared, and the MS analysis was carried out according to our previously reported method (Duncan etal. 2009, Maeda etal. 2013a). Briefly, the samples (rat blood and adrenal glands) were homogenised with acetonitrile, and the supernatants were purified using two columns. For the identification of the steroids and conjugates in the samples, the various compounds present in the blood and adrenal gland preparations were separated using HPLC (UFLC Nexera; Shimadzu, Kyoto, Japan) and an L-column 2 (C18, $2.1 \times 150 \mathrm{~mm}, 2 \mathrm{~mm}$ particle size; Chemicals Evaluation and Research Institute, Tokyo, Japan) at a flow rate of $200 \mu \mathrm{l} / \mathrm{min}\left(40^{\circ} \mathrm{C}\right)$. The chemical formula for each steroid was calculated and identified via LC-TOF MS (microTOF-QII; Bruker Daltonics, Bremen, Germany) using mass error and SigmaFit, as previously reported (Maeda et al. 2013a). Finally, the steroid levels were quantified with LC-MS/MS (LC: Ultimate 3000, MS: TSQ Quantum Ultra; Thermo Fisher Scientific, San Jose, CA, USA) as described in our previous report (Maeda et al. 2013a).

\section{Adrenocorticotrophic hormone determination}

Adrenocorticotrophic hormone (ACTH) peptides digested with trypsin were separated and identified using nanoLCCaptivespray-micrOTOFQII (Bruker Daltonics) and then quantified with LC-MS/MS analysis as shown in
Supplementary Fig. 1-1, see section on supplementary data given at the end of this article by a method based on techniques described in previous reports (Kuzyk et al. 2009, Harbourt et al. 2012). The concentration of the serum peptide ACTH was determined by the standard addition procedure (Stuber \& Reemtsma 2004) using the highest peak '1013.5/505' shown in Supplementary Fig. 12 , and the calibration curve was obtained accurately, as shown in Supplementary Fig. 1-3.

\section{Quantitative RT-PCR}

The quantitative expression of the StAR (F primer, 5'-ggaaggctggaagaaggaaa-3'; R primer, 5'-acacctggcaccaccttact- $\left.3^{\prime}\right)$, peripheral benzodiazepine receptor $(P B R(A C B D 3)$; $\mathrm{F}$ primer, 5'-gaaaccctcctggcatcc-3'; R primer, 5'-tccagattatgtaggagccatacc- $3^{\prime}$ ) and cytochrome P450scc (P450SCC (CYP11A1); F primer, 5'-acctattccgctttgcctt-3'; R primer, $5^{\prime}$-cacgatctcctccaacatcc-3') mRNAs in the adrenal gland and POMC mRNA (F primer, 5'-aggacctcaccacggaaag-3'; $\mathrm{R}$ primer, 5'-ccgagaggtcgagtctgc-3') in the pituitary gland were investigated using real-time RT-PCR with the QuantiTect SYBR Green PCR Kit (Qiagen) and the iQ5/MyiQ Single-Color System (Bio-Rad Laboratories, Inc.). $\beta$-actin (F primer, 5'-ctaaggccaaccgtgaaaag-3'; R primer, $5^{\prime}$-gcctggatggctacgtaca-3') was used as the internal standard. The copy number of each transporter gene was divided by that of $\beta$-actin for normalisation. The quantitative values are the mean \pm s.E.M. of four amplifications.

\section{Western blot analysis}

The adrenal gland tissue was gently homogenised in a $0.25 \mathrm{M}$ sucrose solution $(200 \mu \mathrm{l})$ at $4{ }^{\circ} \mathrm{C}$ and then centrifuged at $900 \mathrm{~g}$ for $10 \mathrm{~min}$ at $4^{\circ} \mathrm{C}$. The resulting supernatant was centrifuged at $5000 \mathrm{~g}$ for $10 \mathrm{~min}$ at $4{ }^{\circ} \mathrm{C}$. The final supernatant was used as the cell lysate, and the precipitate was used as the mitochondrial fraction. The protein concentration of the cell lysate and the mitochondrial fraction were estimated using the Lowry protein assay (Lowry et al. 1951). The cell lysate for the detection of LDL receptor (LDLR) and scavenger receptor type B1 (SR-B1) and the mitochondrial fraction for the P450scc were separated via SDS-PAGE and then transferred to PVDF membranes (ATTO, Tokyo, Japan) for western blot analysis. The membranes were probed with the following primary antibodies as described previously (Sakaguchi et al. 2013): rabbit polyclonal antibody against rat P450scc (purchased from Millipore Corp. (Billerica, MA, USA), AB1244) as described previously (Maeda et al. 2013b), SR-B1 (Sigma-Aldrich), chicken polyclonal antibody

Published by Bioscientifica Ltd. 
against LDLR (Sigma-Aldrich) and rabbit polyclonal antibody against $\beta$-actin (Abcam, Cambridge, UK). The expression levels of each protein were analysed densitometrically using CS Analyzer ver 3.0 (ATTO).

\section{Enzymatic activity assay of cholesterol side chain cleavage reaction}

Enzymatic activities were assayed as described previously (Maeda et al. 2013b) using a 20-hydroxycholesterol as a substrate, and the reaction product, pregnenolone, was identified as shown in Supplementary Fig. 2, see section on supplementary data given at the end of this article, and determined using MS analysis (Maeda et al. 2013a).

\section{Cholesterol analysis}

The total cholesterol level in the adrenal gland was assayed using the Cholesterol E Kit (Wako, Osaka, Japan) with cholesterol oxidase and cholesterol esterase. Free cholesterol was determined using the same procedure without cholesterol esterase. The cholesterol ester level was calculated using the total and free cholesterol levels. The adrenal gland tissue was gently homogenised in a $0.25 \mathrm{M}$ sucrose solution $(200 \mu \mathrm{l})$, followed by centrifugation at $900 \boldsymbol{g}$ for $10 \mathrm{~min}$. The amount of total cholesterol in the resulting supernatant was assayed according to the manufacturer's protocol. The total cellular cholesterol and free cholesterol were determined after disrupting the organelle membranes with a $0.25 \mathrm{M}$ sucrose solution containing 0.1\% CHAPS and 0.1\% SDS.

\section{Statistical analysis}

Results are expressed as the mean \pm s.E.M. of three to five independent experiments. Statistical analysis was carried out using the $F$-test and Student's $t$-test.

\section{Results}

\section{Tissue distribution of DES}

A single dose of DES was orally administered to adult male rats $(0.1 \mathrm{mg} \mathrm{DES} / \mathrm{rat})$. After $1 \mathrm{~h}$ of treatment, the DES concentration in various organs was determined using an accurate LC-MS-based method that was previously developed by our group (Maeda et al. 2013a), and the results are shown in Fig. 1. Interestingly, a high level of DES was observed in the liver, adrenal glands and pituitary gland (Fig. 1).

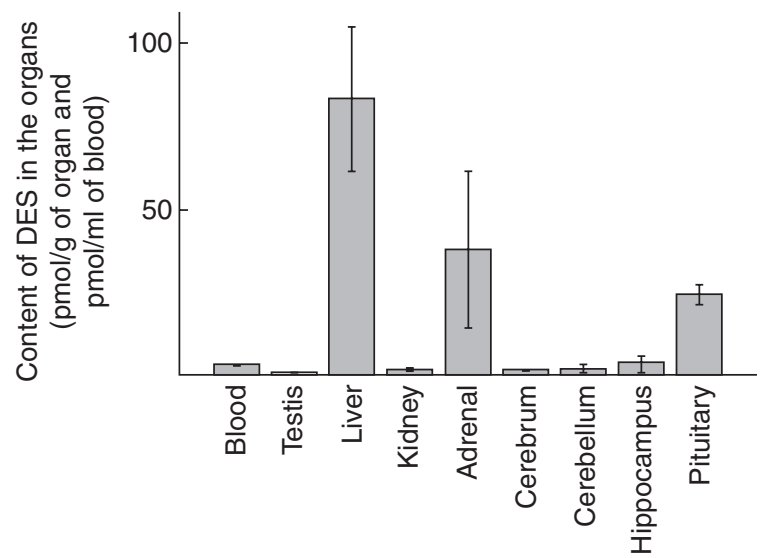

Figure 1

Distribution of DES after $1 \mathrm{~h}$ of treatment. A single dose of DES was orally administered to adult male rats $(0.1 \mathrm{mg} / \mathrm{rat})$, and the amount of DES in various organs was determined via LC-MS analysis using our previously reported protocol (Maeda et al 2013a). One gland or organ of five rats was used for the experiments. The data for each point represent the mean \pm S.E.M. of five of each organ.

\section{Weight of the adrenal glands and other organs}

Larger adrenal glands were observed in rats treated with DES for 2 weeks compared with rats that had undergone the control treatment, as shown in Fig. 2A. In addition, the dry weight and the total protein content of the adrenal gland were higher in the rats treated with DES compared with the control rats (Fig. 2B and C). The body and organ weights of the adult male rats that were orally administered DES $(0.1 \mathrm{mg} / \mathrm{rat}$ every 2 days) for 2 weeks were measured, and the body and testis weights were found to be decreased as a result of DES administration (Fig. 2D). However, the only weight increase was observed for the adrenal gland, which was $\sim 1.3$-fold heavier after only 1 week of DES exposure (Fig. 2D).

\section{Histological observation of the adrenal glands}

Adrenal gland tissue sections from the rats that were administered DES for 2 weeks were stained with HE (Fig. 3A, B, C, D, E and F). Adrenal hypertrophy was observed in the zona fasiculata (ZF) and zona reticularis (ZR) of DES-treated rats (Fig. 3A, B, C and D). In the adrenal cortex, the droplet size was smaller as a result of DES administration, as shown in Fig. 3E and F.

\section{Levels of corticosterone, ACTH and POMC}

The corticosterone levels in the blood of rats treated with DES for 1 or 2 weeks were assayed according to a previously reported protocol (Maeda et al. 2013a). The control

Published by Bioscientifica Ltd 


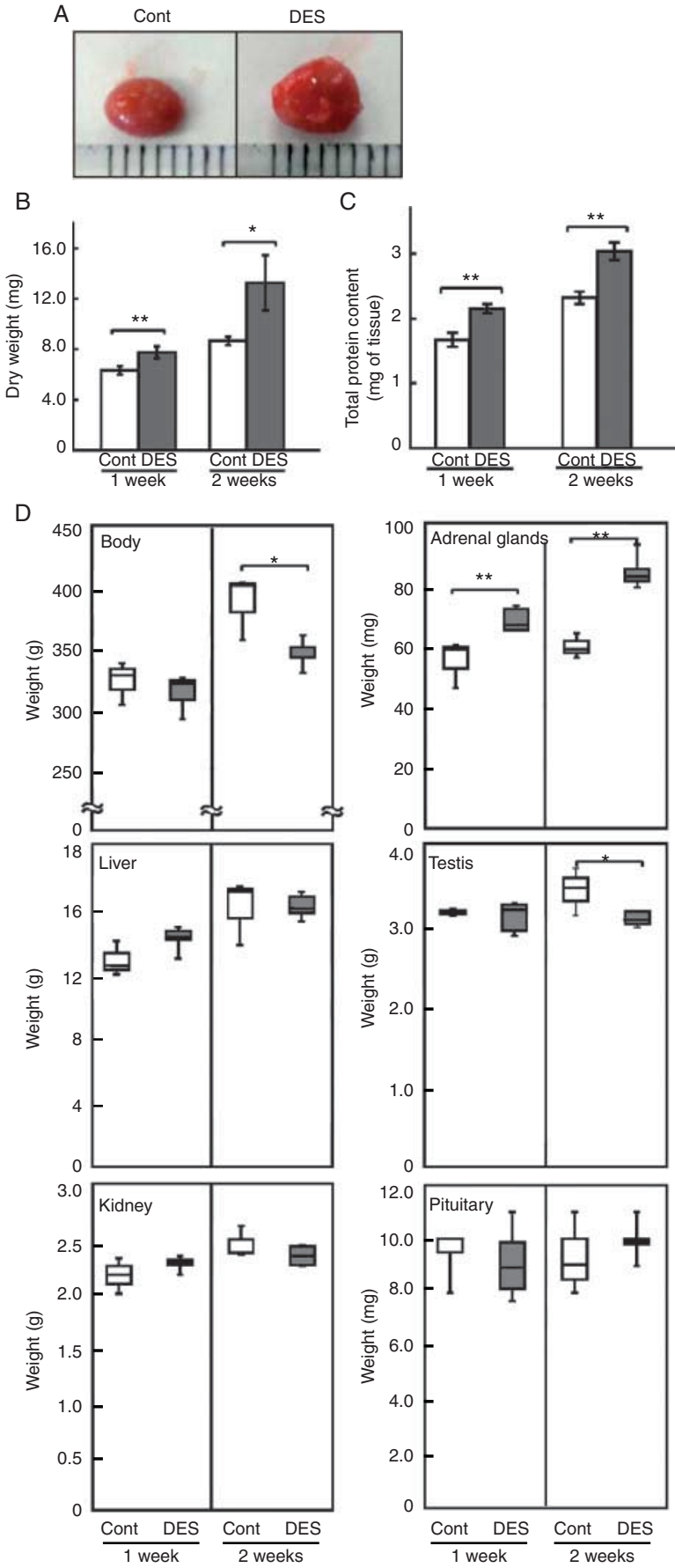

Figure 2

Effects of diethylstilbestrol (DES) treatment on the gross morphology of the adrenal gland. DES was orally administered to male rats $(0.1 \mathrm{mg} / \mathrm{rat}$ every 2 days) for 1 and 2 weeks. Rats treated only with olive oil were used as controls (Cont). Photographs (A) of an adrenal gland of a rat treated with DES for 2 weeks and an adrenal gland from a control rat. The adrenal gland was dried using a vacuum dryer, and the dry weight is shown (B). The total protein content in the $900 \mathrm{~g}$ supernatant of the adrenal homogenate is also shown (C). The body and organ weights are shown in (D). The data for each group represent the mean \pm s.E.M. of three to four rats. ${ }^{*} P<0.05$ and $* * P<0.01$ compared with controls.

http://joe.endocrinology-journals.org DOI: $10.1530 / J O E-13-0460$ levels showing $\sim 100 \mathrm{ng} / \mathrm{ml}$ of blood were corroborated with data obtained previously via RIA (Henning 1978, Besedovsky et al. 1981). The corticosterone levels in the blood showed a clear decrease after only 1 week of treatment, as shown in Fig. 4A. The levels of serum ACTH and pituitary Pomc mRNA were also assayed, and the results are shown in Fig. 4B and C. Unexpectedly, the ACTH concentration was unchanged, and the expression of Pomc mRNA, which encodes the protein that produces the ACTH peptide in the pituitary gland, was also not induced. Other serum factors (glucose, creatinine and electrolytes) were observed to display no alterations (data not shown).

\section{Levels of corticosteroids and their precursors in the adrenal glands}

The levels of corticosterone, aldosterone and the biosynthetic corticosterone precursors in the organs of the DES-treated rats were assayed, and the levels in the adrenal glands are shown in Fig. 5. Corticosterone and all of the corticosterone precursors except for deoxycorticosterone decreased significantly after 1 week of DES treatment. Aldosterone and 18-hydroxycorticosterone also decreased after 1 week of treatment, as shown in Fig. 5.

\section{Rate-limiting factors in adrenal steroidogenesis and levels of SR-B1 and LDLR}

The transport of cholesterol into the mitochondria, which is mediated by Star and $\mathrm{Pbr}$, is the rate-limiting process of steroidogenesis (Hauet et al. 2002, Miller 2013). The mRNA levels of the proteins that mediate these rate-limiting reactions were assayed using RT-PCR, and the results are shown in Fig. 6. In the adrenal glands of the rats treated with DES for 1 week, the relative gene expression levels of Star and Pbr tended to increase (Fig. 6A and B). Recently, we have found that an initial target of DES in testicular steroidogenesis dysfunction is the reduction in the expression and the enzyme activity of P450scc (Maeda et al. 2013b). In the case of the adrenal, the mRNA expression level of P450scc tended to increase after a 1-week of treatment with DES (Fig. 6C). The P450scc protein expression level and the enzymatic activity of the cholesterol side chain cleavage reaction were also slightly increased after 1 week of treatment with DES, as shown in Fig. 6D and E. The expression of LDLR and SR-B1 (HDL receptor (HDLR)) was examined using western blot analysis with specific antibodies, and the results are shown in Fig. 7A. LDLR and SR-B1 were induced twofold

Published by Bioscientifica Ltd. 
A

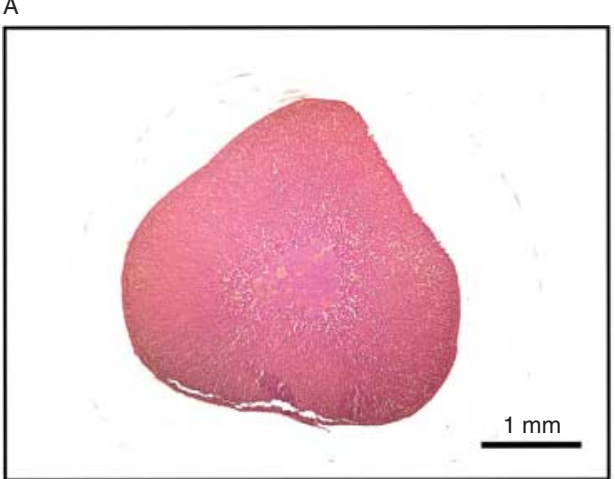

C

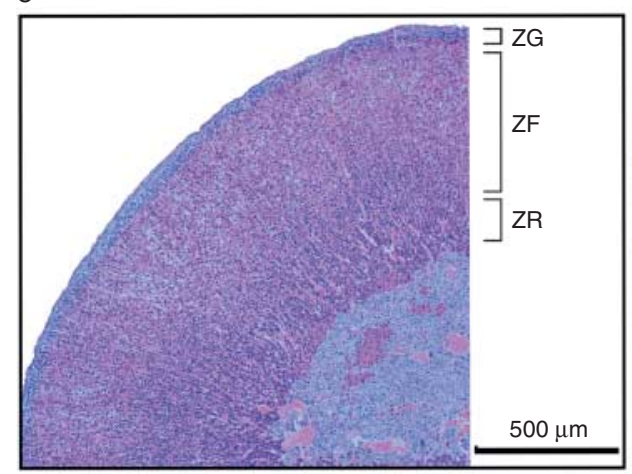

$\mathrm{E}$

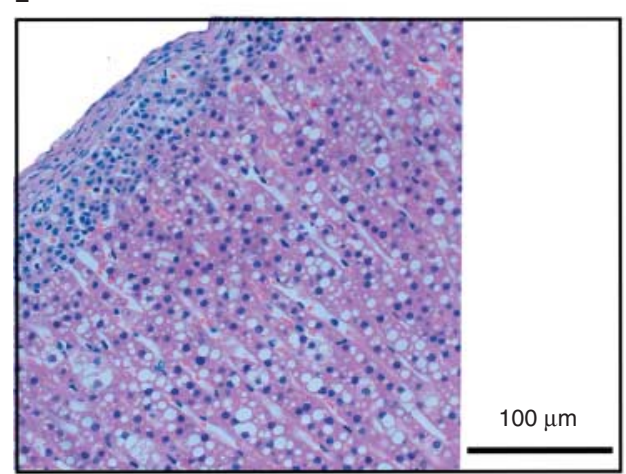

$B$

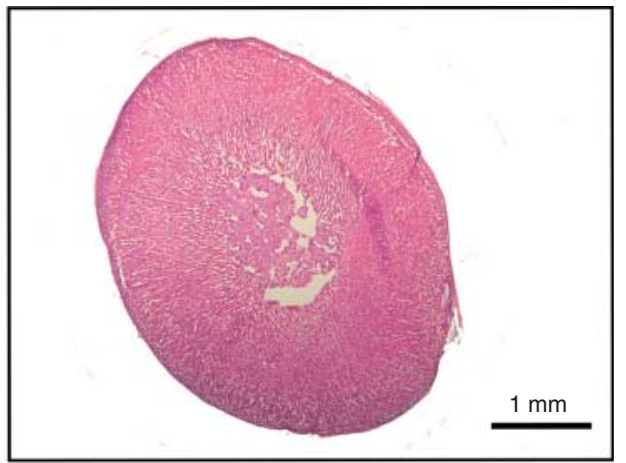

$\mathrm{D}$

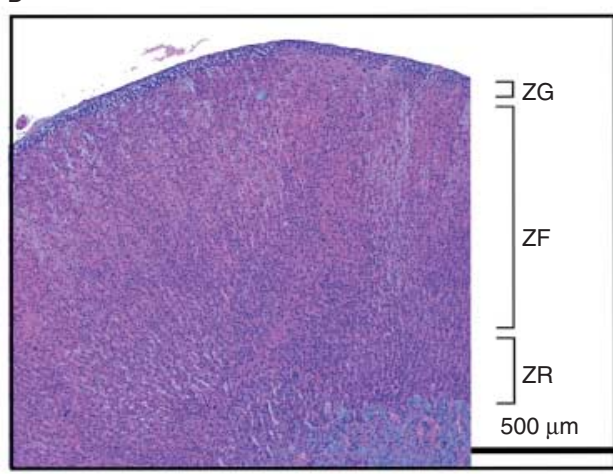

$\mathrm{F}$

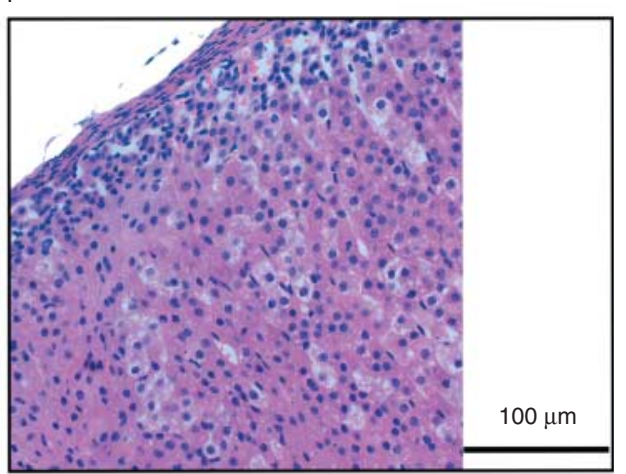

Figure 3

Histological analysis of the adrenal gland in rats treated with DES for 2 weeks. Haematoxylin and eosin staining of the adrenal gland in control rats treated with only olive oil (A, C and E) and rats treated with DES for

and three- to fourfold in the adrenal glands of the DEStreated rats, respectively, as shown in Fig. 7B.

\section{Cholesterol in the adrenal glands}

The results of the Oil Red O staining of the adrenal cortex are shown in Fig. 8A, B, C, D, E and F. The fat droplets, which are dyed bright red, clearly decreased in the adrenal
2 weeks ( $B, D$ and $F$ ) is shown. Adrenal cortex divided into zona glomerulosa (ZG), zona fasciculata (ZF) and zona reticularis (ZR) is shown $(C$ and $D)$. Each group (control and DES) contained three to four rats.

cortex as a result of the administration of DES for 2 weeks (Fig. 8B, D and F). To examine the tissue and cellular changes in more detail, we carried out a histopathological analysis using an electron microscope and verified that the droplets were smaller in the adrenal cortex following the 2-week treatment (Fig. 8G and H). The total cholesterol and free cholesterol in the adrenal glands were measured following DES administration for 1 or 2 weeks (Fig. 8I).

Published by Bioscientifica Ltd. 
A

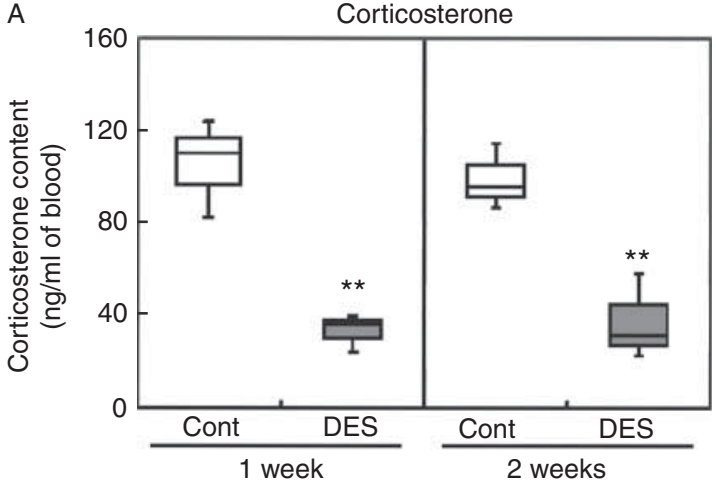

B
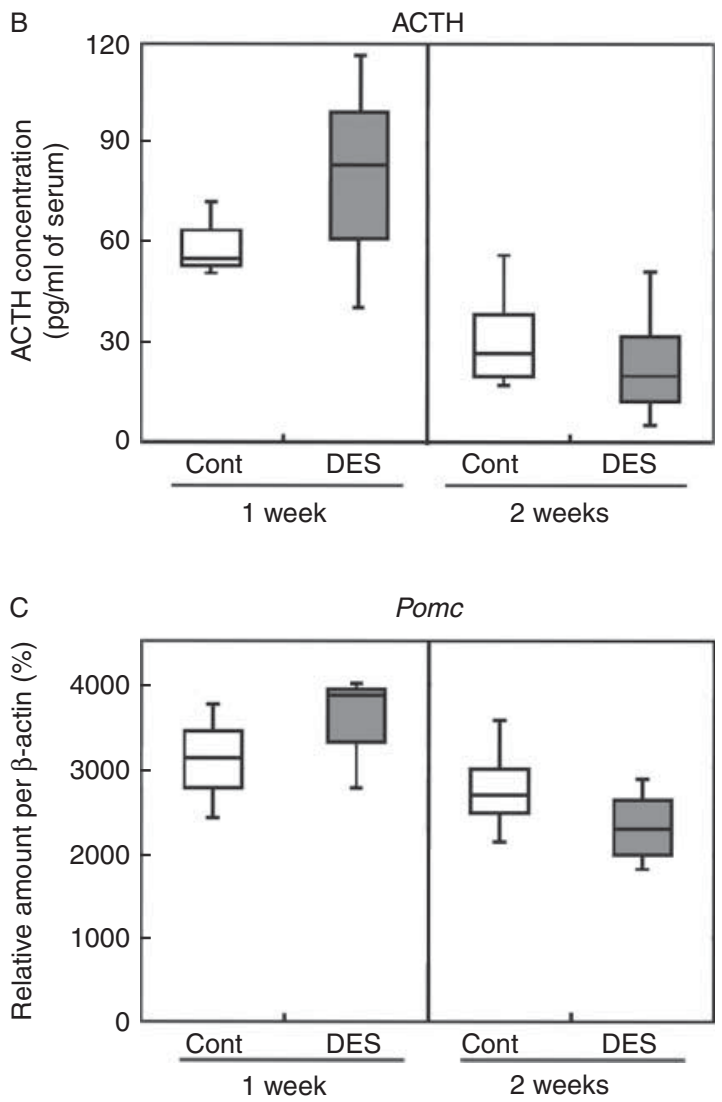

Figure 4

Levels of corticosterone and ACTH in the serum. Diethylstilbestrol (DES) was orally administered to adult male rats ( $0.1 \mathrm{mg} /$ rat every 2 days) for 1 and 2 weeks (DES). Rats treated only with olive oil were used as controls (Cont). The corticosterone levels (A) in the blood and serum ACTH levels (B) were determined via LC-MS analysis as described previously (Maeda et al 2013a) and as described in the 'Materials and methods' section and Supplementary Figs 1 and 2. Pituitary Pomc mRNA (C) was analysed as described in the 'Materials and methods' section. The data for each group represent the mean \pm S.E.M. of three to four rats. ${ }^{*} P<0.01$ compared with controls.

As shown in Fig. 8A, B, C, D, E, F, G, H and I, the free cholesterol level and the cholesterol ester level calculated from the levels of total and free cholesterol significantly decreased in the adrenal droplets of DES-treated rats.

\section{Discussion}

Our dose of $\sim 0.34 \mathrm{mg} / \mathrm{kg}$ of body weight $(0.1 \mathrm{mg} / \mathrm{rat})$ every 2 days for 1 or 2 weeks is based on results from our previous study where we had examined the effects of two doses of DES $(0.1 \mathrm{mg} / \mathrm{rat}$ every 2 days and $1.0 \mathrm{mg} /$ rat every 2 days) on adult male rats. We found adverse effects on the testicular proteins at the lower dose $(0.1 \mathrm{mg} / \mathrm{rat}$ every 2 days; Li et al. 2011, Maeda et al. 2013b). In this study, we found adrenal abnormalities only after 1 week of treatment with DES $(0.1 \mathrm{mg} / \mathrm{rat}$ every 2 days), and revealed that the endocrine disruptor DES disrupts corticosteroid biosynthesis via cholesterol insufficiency. We have recently developed a method for the accurate determination of steroids and chemicals in organs using LC-MS analysis (Maeda et al. 2013a). In this study, we determined the tissue distribution of DES, and this is the first report, to our knowledge, of its direct detection in organs.
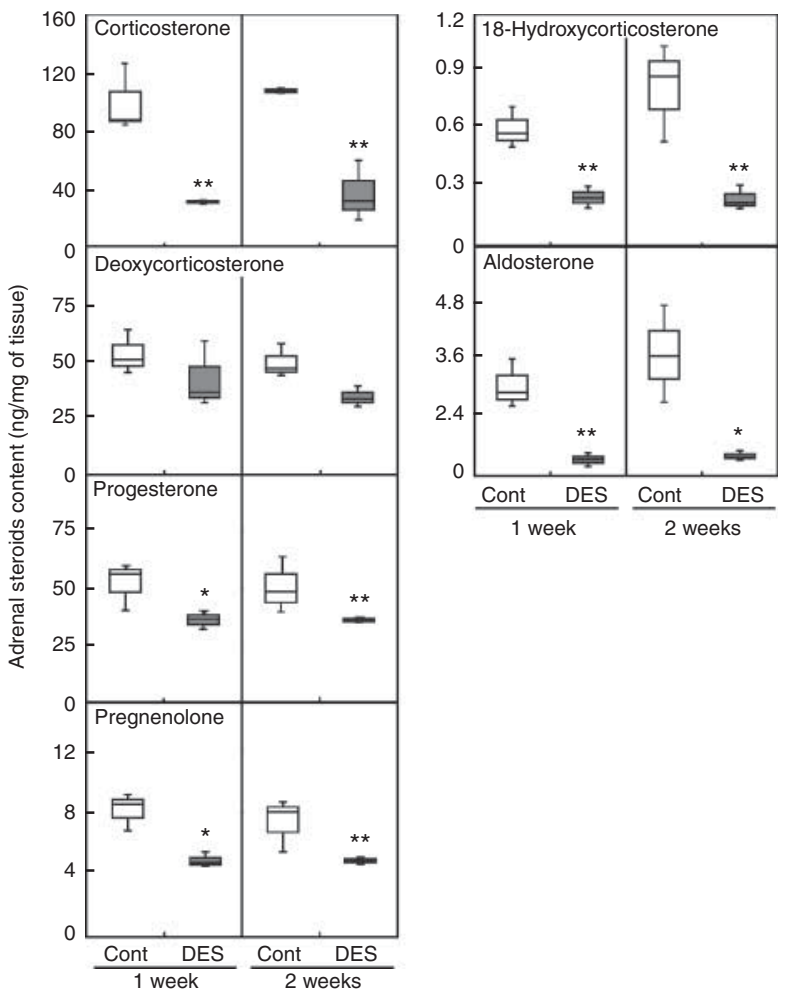

Figure 5

Levels of adrenal corticosterone, and aldosterone and the corticosterone precursors pregnenolone, progesterone, deoxycorticosterone and 18-hydroxycorticosterone. Rats were treated with diethylstilbestrol (DES) $(0.1 \mathrm{mg} / \mathrm{rat}$ every 2 days) for 1 or 2 weeks (DES). Rats treated only with olive oil were used as controls (Cont). The steroid levels were determined via LC-MS analysis as described previously (Maeda et al 2013a) and as described in the 'Materials and methods' section. The data for each group represent the mean \pm s.E.M. of three to four rats. ${ }^{*} P<0.05$ and ${ }^{* *} P<0.01$ compared with controls.

Published by Bioscientifica Ltd. 


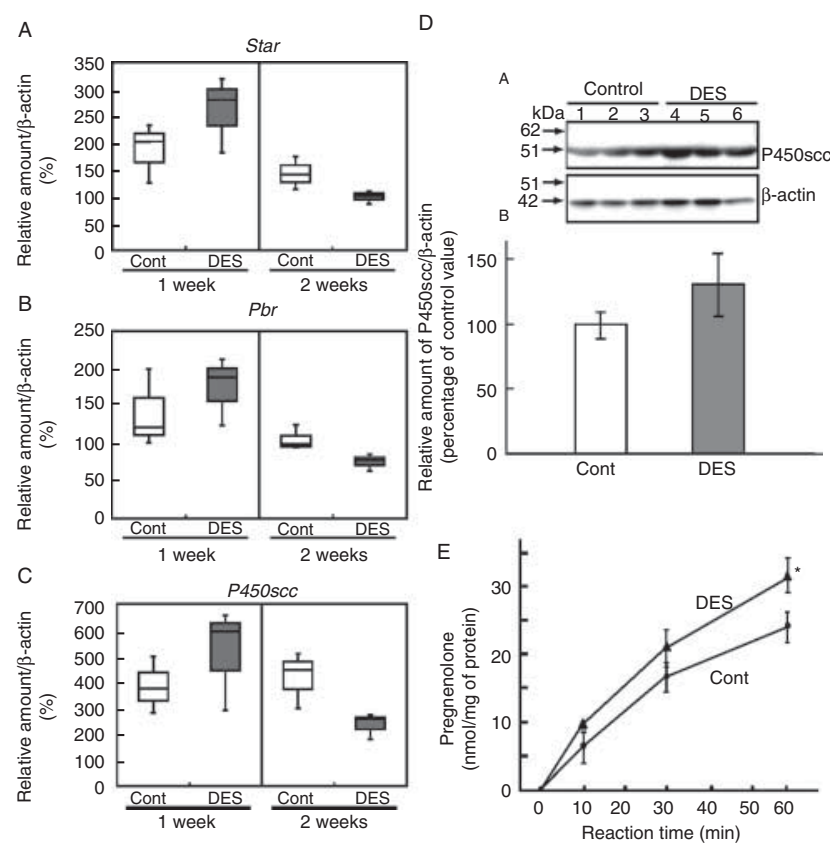

Figure 6

The expression of P450scc, Star and peripheral benzodiazepine receptor $(P b r)$ in the adrenal gland. The adrenal mRNA levels of Star, Pbr and cytochrome P450scc (P450scC) in the DES-treated rats were determined via RT-PCR as described in the 'Materials and methods' section. The rats were treated with DES ( $0.1 \mathrm{mg} /$ rat every 2 days) for 1 and 2 weeks (DES). Rats treated only with olive oil were used as controls (Cont). The data are the relative amount of each mRNA normalised to $\beta$-actin ( $A, B$ and $C$ ). The protein expression levels of mitochondrial P450scc were analysed densitometrically using a CS Analyzer (ATTO), and enzymatic activities of P450scc were analysed using the methods described in the 'Materials and methods' section. The data are shown in (D) and (E) respectively. The data for each group represent the mean \pm S.E.M. of three to four rats. ${ }^{*} P<0.05$ compared with controls.

Our results showed that DES was distributed throughout the body and was present at high levels in the liver, adrenal glands and pituitary gland. The reasons for this specific distribution are unknown, but it may lead to early direct damage in these organs by orally administered DES. We observed early adverse effects of DES on the adrenal glands, as shown in Figs 2, 3, 4, 5, 6, 7 and 8. Our data will contribute to the elucidation of the mechanism of DES toxicity. Although in vitro experiments are useful, in vivo data indicate that an interaction exists among these organs on the basis of the DES distribution data.

We found that DES preferentially accumulates in the adrenal and pituitary glands rather than in the testis, where DES toxicity has been reported in previous studies. The increase in adrenal weight and the decrease in the vacuolisation of the ZF cells observed in all high-dose male groups have also been reported for oestradiol (Biegel et al. 1998) and ethinylestradiol (Andrews et al. 2002). This evidence indicates that the oestrogenic activity of these compounds and DES may reflect a change in adrenal steroid metabolism, leading to the increase in adrenal weight.

It has been recently demonstrated that aldosterone induced dose-dependent increases in testosterone production (Ge et al. 2005). Part of the testicular reproductive toxicity of DES may be indirectly induced upon the decrease in aldosterone level in the DES-treated male rat, as shown in Fig. 5. The adrenal and pituitary glands express high levels of ER $\alpha$ but not ER $\beta$ (Kuiper et al. 1997) and DES can bind to both ER $\alpha$ and ER $\beta$ with equal affinity (Kuiper et al. 1997). However, the reproductive toxicity of DES acts in an ER $\alpha$-dependent manner in mice (Henley \& Korach 2006), indicating that DES has a higher affinity for ER $\alpha$-expressing organs such as the adrenal and pituitary glands. The adrenal glands may be the principal target of DES. In addition, in this study, the dry weight of the adrenal glands completely agreed with their wet weight (Fig. 2), and the total protein content in the $900 \mathrm{~g}$ supernatants of the adrenal homogenates were also consistent with the wet weight data, indicating that the increase in the adrenal weight as a result

A
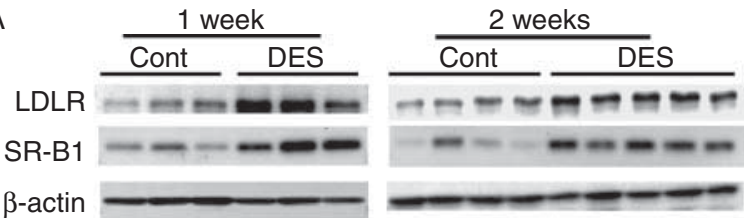

B

1 week
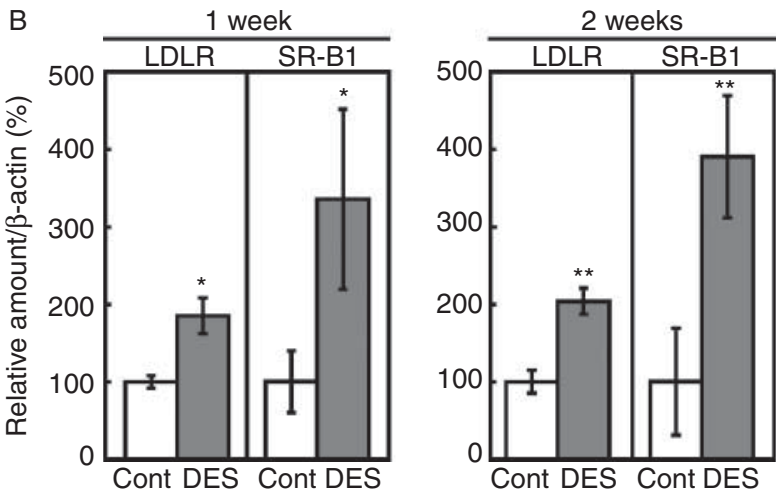

Figure 7

Levels of SR-B1 and LDL receptor (LDLR). The protein expression levels of the HDL receptor (SR-B1) and the LDLR were assayed via western blot analysis using specific antibodies as described in the 'Materials and methods' section (A). (B) Each band for the control rats (Cont; three to four animals) and for the DES-treated rats (DES; three to five animals) was analysed densitometrically using a CS Analyzer (ATTO), and the expression levels of LDLR and SR-B1 were induced approximately twofold (LDLR) and 3.4- to 3.9-fold (SR-B1) respectively. The data for each group represent the mean \pm S.E.M. of three to four rats. ${ }^{*} P<0.05$ and $* * P<0.01$ compared with the control. 
of DES treatment was due to the hypertrophy of adrenal tissue, as demonstrated by our histological observations (Fig. 3). The adverse effects of DES described earlier were observed in adult male rats that were administered DES $(0.1 \mathrm{mg} /$ rat every 2 days) for 2 weeks. Some studies have reported that lipid accumulation results in adrenal hyperplasia (Cummins et al. 2006, Miller \& Bose 2011). Uniquely, the enlarged adrenal glands in rats treated with DES contained lower levels of cholesterol. In addition, the levels

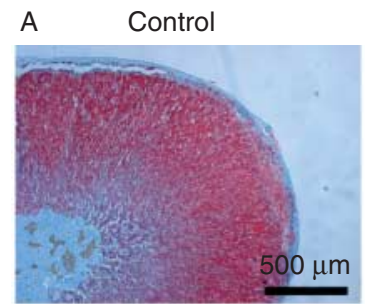

C

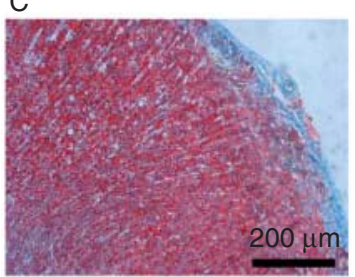

E

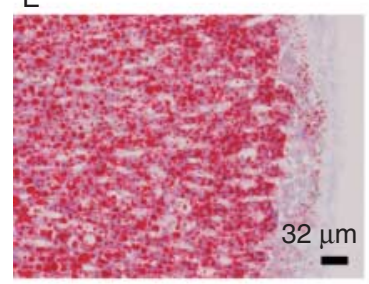

G

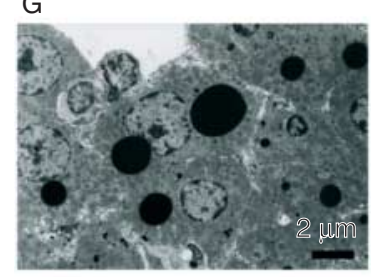

।

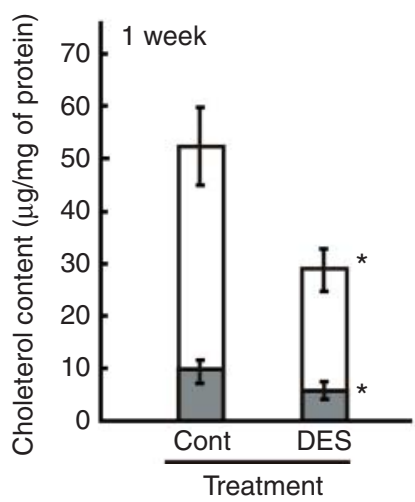

http://joe.endocrinology-journals.org DOI: 10.1530/JOE-13-0460

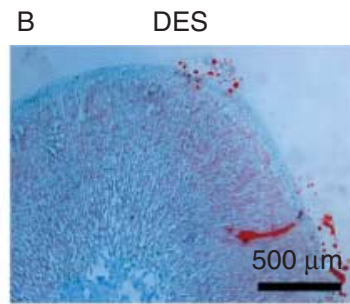

D

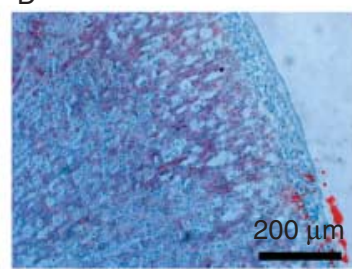

$\mathrm{F}$

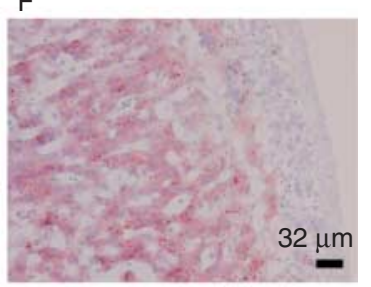

$\mathrm{H}$
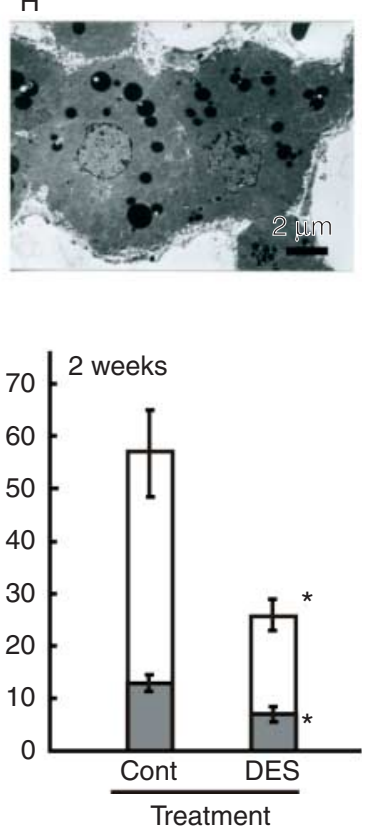

๑) 2014 Society for Endocrinology Printed in Great Britain of adrenal corticosterone and its precursors decreased after 1 week of DES administration without any morphological abnormalities being observed (data not shown). These results indicate that hypertrophy of the adrenal glands may have resulted from the ACTH feedback induced by low plasma corticosterone levels. However, the serum ACTH levels and pituitary Pomc mRNA were not increased by DES treatment in this study. It has been reported that DES-diphosphate (500 or $1000 \mathrm{mg} /$ day for $2-5$ weeks) suppressed the serum level of testosterone for the treatment of prostate cancer patients without significant effect on serum levels of ACTH (Kitahara et al. 1999). Recently another factor for adrenal development has been reported. The expression level of the transcription factor $S f 1$ (steroidogenic factor 1) was stimulated in the ovaries of neonatally DES-treated 3-month-old mice (Kakuta et al. 2012). SF1 is essential for normal development and function of the adrenal glands, and overexpression of $S f 1$ results in adrenal hyperplasia (Gardiner et al. 2012). Further study is required to elucidate the mechanism underlying the hypertrophy of adrenal glands induced by DES.

Congenital lipid adrenal hyperplasia, which is characterised by severe deficiencies in steroidogenesis, is known to result from Star and P450scc mutations (Miller \& Bose 2011). Cholesterol, which has a 17 -carbon steroid nucleus, is the starting material for adrenal steroidogenesis, which produces corticosterone, aldosterone and adrenal androgens. For adrenal steroidogenesis, cytosolic cholesterol

\section{Figure 8}

Cholesterol in the adrenal gland. Cryosections of the adrenal cortex were stained with Oil Red O for neutral lipids and counterstained with haematoxylin for nuclei. (A, B, C, D, E and F). Electron microscopic images of the cells of the zona fasciculata in adrenal glands from control (G) and DES-treated $(\mathrm{H})$ rats are also provided. The amount of total cholesterol and free cholesterol in the adrenal glands of rats treated with DES for 1 and 2 weeks were also determined (I). The free cholesterol (gray columns) was determined using cholesterol oxidase, and the total cholesterol (whole columns) was determined using the oxidase and cholesterol esterase after the destruction of the organelle membranes in the presence of $0.1 \%$ CHAPS and $0.1 \%$ SDS, as described in the 'Materials and methods' section. The free cholesterol levels (gray columns) were $\sim 10.36 \pm 0.37 \mu \mathrm{g} / \mathrm{mg}$ of protein in control rats after 1 week, $5.43 \pm 0.46 \mu \mathrm{g} / \mathrm{mg}$ of protein in rats treated with DES for 1 week, and $12.42 \pm 0.33 \mu \mathrm{g} / \mathrm{mg}$ of protein in control rats after 2 weeks, $6.31 \pm 0.45 \mu \mathrm{g} / \mathrm{mg}$ of protein in rats treated with DES for 2 weeks. The levels of cholesterol ester (white columns) calculated using total and free cholesterol levels were $\sim 44.40 \pm 3.64 \mu \mathrm{g} / \mathrm{mg}$ of protein in control rats after 1 week, $27.82 \pm 1.65 \mu \mathrm{g} / \mathrm{mg}$ of protein in rats treated with DES for 1 week, and $47.88 \pm 3.63 \mu \mathrm{g} / \mathrm{mg}$ of protein in control rats after 2 weeks, $21.09 \pm 3.22 \mu \mathrm{g} / \mathrm{mg}$ of protein in rats treated with DES for 2 weeks. Significant differences in the cholesterol ester levels at 1 and 2 weeks of treatment were observed between control and DES-treated rats. The data for each group represent the mean \pm S.E.M. of three to five rats. ${ }^{*} P<0.05$ compared with the control rats.

Published by Bioscientifica Ltd. 
is transported into the mitochondria by StAR and PBR as the rate-limiting step in steroid hormone biosynthesis. Cytosolic cholesterol is then converted to pregnenolone by P450scc. This enzyme system converts cholesterol to pregnenolone and determines the net steroidogenic capacity. Thus, it serves as the chronic regulator of steroidogenesis. Unfortunately, the expression levels of Star, Pbr and P450scc tended to increase upon DES treatment (Fig. 6), indicating that cholesterol transport and conversion to pregnenolone are not the cause of the observed adrenal insufficiency and the decrease in corticosterone biosynthesis produced by DES. Therefore, we examined the possibility that low cholesterol may cause the DES-promoted changes in the expression of the HDLR and LDLR. The cholesterol used for adrenal steroidogenesis is primarily obtained via SR-B1 (HDLR)-mediated uptake from serum HDL-cholesterol in rodents (Kraemer 2007). The expression of the SR-B1 and LDLR was analysed using western blotting with specific antibodies, and the receptors were found to be increased in the adrenal glands of DES-treated rats, as shown in Fig. 7, indicating that the system by which cholesterol is taken up from the blood may not function efficiently even upon their induction. Therefore, we examined why corticosterone biosynthesis is suppressed despite the expression levels of both receptors being induced. Decreased adrenal corticosterone synthesis was linked to the cholesterol content in the adrenal gland. The mechanism by which adrenal cholesterol is decreased upon DES treatment remains unclear; however, DES was shown to disrupt the cholesterol supply for optimal corticosterone synthesis. The mechanism of DES toxicity in the adrenal glands appears to be distinct from that in the testis, as has been previously reported by us, in which DES influences the proteins associated with steroidogenesis (including P450scc (Maeda et al. 2013b)) but does not disrupt cholesterol content of the testis (data not shown). Plasma lipoprotein deficiency in mice as a result of feeding with probucol is associated with decreased adrenal cortex cholesterol levels, a lower basal and stress-induced plasma glucocorticoid level (Hoekstra et al. 2010). Recently, in low-HDL-cholesterol subjects, adrenal steroids have been reduced to about $30 \%$ of the normal values for controls due to insufficiency of the source for adrenal steroidogenesis (Bochem et al. 2013). These previous studies and our results in this study support the hypothesis that reduction of adrenal steroidogenesis is due to adrenal cholesterol insufficiency, which might be caused by the reduction in serum $\mathrm{HDL} /$ cholesterol level in DES-treated rats. To explore the mechanism by which adrenal cholesterol is reduced, further study of serum lipoproteins and cholesterol using short-term DES administration is required.

Adrenal steroids play important roles not only in foetal and neonatal growth and development but also in labour and childbirth (Chida et al. 2011, Kaludjerovic \& Ward 2012). Therefore, chronic corticosterone suppression induced by DES has the potential to disrupt the regulators of endocrine homeostasis and to facilitate the impairment of stress resistance. These findings constitute a new and important step towards understanding the mechanisms behind DES toxicity, such as reduced fertility, increased vaginal adenocarcinoma, and reduced testicular size and sperm count (Schrager \& Potter 2004, Shin et al. 2009, Unüvar \& Büyükgebiz 2012). It is difficult to elucidate the mechanism of DES toxicity over the long term from the foetal stage to adulthood due to multiple hormone-related events such as foetal development, delivery and puberty. The adult exposure used in this study was used to reveal some of the direct adverse effects of DES. The adrenal insufficiency and cholesterol imbalance found in this study should be the key targets for investigation of the mechanism of DES toxicity in pregnant animals and foetuses in the future. In addition, DES administration has the potential to disrupt cholesterol homeostasis, which is strictly controlled in vivo.

In conclusion, we have shown that DES disrupts corticosteroid biosynthesis via adrenal cholesterol insufficiency. The elucidation of the detailed mechanism behind this new adverse effect may reveal an association between chemical intake and various diseases due to cholesterol imbalance.

Supplementary data

This is linked to the online version of the paper at http://dx.doi.org/10.1530/ JOE-13-0460.

\section{Declaration of interest}

The authors declare that there is no conflict of interest that could be perceived as prejudicing the impartiality of the research reported.

\section{Funding}

This work was supported in part by the Supported Program for the Strategic Research Foundation at Private Universities (2013-2017) of the Ministry of Education, Culture, Science and Technology, Japan.

\section{Acknowledgements}

The authors are thankful to Emi Tanaka and Kanae Masu for their technical help with measurements of hormone concentrations via LC-MS.

Published by Bioscientifica Ltd. 


\section{References}

Andrews P, Freyberger A, Hartmann E, Eiben R, Loof I, Schmidt U, Temerowski M, Folkerts A, Stahl B \& Kayser M 2002 Sensitive detection of the endocrine effects of the oestrogen analogue ethinylestradiol using a modified enhanced subacute rat study protocol (OECD Test Guideline no. 407). Archives of Toxicology 76 194-202. (doi:10.1007/ s00204-002-0337-7)

Besedovsky HO, del Rey A \& Sorkin E 1981 Lymphokine-containing supernatants from con A-stimulated cells increase corticosterone blood levels. Journal of Immunology 126 385-387.

Biegel LB, Flaws JA, Hirshfield AN, O'Connor JC, Elliot GS, Ladics GS, Silbergeld EK, Van Pelt CS, Hurtt ME, Cook JC et al. 1998 90-Day feeding and one-generation reproduction study in Crl:CD BR rats with 17b-estradiol. Toxicological Sciences 44 116-142.

Bochem AE, Holleboom AG, Romijn JA, Hoekstra M, Dallinga-Thie GM, Motazacker MM, Hovingh GK, Kuivenhoven JA \& Stroes ES 2013 High density lipoprotein as a source of cholesterol for adrenal steroidogenesis: a study in individuals with low plasma HDL-C. Journal of Lipid Research 54 1698-1704. (doi:10.1194/jlr.P033449)

Chida D, Miyoshi K, Sato T, Yoda T, Kikusui T \& Iwakura Y 2011 The role of glucocorticoids in pregnancy, parturition, lactation, and nurturing in melanocortin receptor 2-deficient mice. Endocrinology 152 1652-1660. (doi:10.1210/en.2010-0935)

Cummins CL, Volle DH, Zhang Y, McDonald JG, Sion B, LefrançoisMartinez AM, Caira F, Veyssière G, Mangelsdorf DJ \& Lobaccaro JM 2006 Liver X receptors regulate adrenal cholesterol balance. Journal of Clinical Investigation 116 1902-1912. (doi:10.1172/JCI28400)

Dean RT, Fu S, Stocker R \& Davies MJ 1997 Biochemistry and pathology of radical-mediated protein oxidation. Biochemical Journal 324 1-18.

Diamanti-Kandarakis E, Bourguignon JP, Giudice LC, Hauser R, Prins GS, Soto AM, Zoeller RT \& Gore AC 2009 Endocrine-disrupting chemicals: an Endocrine Society scientific statement. Endocrine Reviews 30 293-342. (doi:10.1210/er.2009-0002)

Duncan MW, Yergey AL \& Patterson SD 2009 Quantifying proteins by mass spectrometry: the selectivity of SRM is only part of the problem. Proteomics 9 1124-1127. (doi:10.1002/pmic.200800739)

Gardiner JR, Shima Y, Morohashi K \& Swain A 2012 SF-1 expression during adrenal development and tumourigenesis. Molecular and Cellular Endocrinology 351 12-18. (doi:10.1016/j.mce.2011.10.007)

Ge RS, Dong Q, Sottas CM, Latif SA, Morris DJ \& Hardy MP 2005 Stimulation of testosterone production in rat Leydig cells by aldosterone is mineralocorticoid receptor mediated. Molecular and Cellular Endocrinology 243 35-42. (doi:10.1016/j.mce.2005.08.004)

Giusti RM, Iwamoto K \& Hatch EE 1995 Diethylstilbestrol revisited: a review of the long-term health effects. Annals of Internal Medicine 122 778-788. (doi:10.7326/0003-4819-122-10-199505150-00008)

Harbourt DE, Fallon JK, Ito S, Baba T, Ritter JK, Glish GL \& Smith PC 2012 Quantification of human uridine-diphosphate glucuronosyl transferase $1 \mathrm{~A}$ isoforms in liver, intestine, and kidney using nanobore liquid chromatography-tandem mass spectrometry. Analytical Chemistry $\mathbf{8 4}$ 98-105. (doi:10.1021/ac201704a)

Hauet T, Liu J, Li H, Gazouli M, Culty M \& Papadopoulos V 2002 PBR, StAR, and PKA: partners in cholesterol transport in steroidogenic cells. Endocrine Research 28 395-401. (doi:10.1081/ERC-120016814)

Henley DV \& Korach KS 2006 Endocrine-disrupting chemicals use distinct mechanisms of action to modulate endocrine system function. Endocrinology 147(Suppl 6) S25-S32. (doi:10.1210/en.2005-1117)

Henning SJ 1978 Plasma concentrations of total and free corticosterone during development in the rat. American Journal of Physiology 235 E451-E456.

Hillered L \& Ernster L 1983 Respiratory activity of isolated rat brain mitochondria following in vitro exposure to oxygen radicals. Journal of Cerebral Blood Flow and Metabolism 3 207-214. (doi:10.1038/jcbfm.1983.28)
Hoekstra M, Korporaal SJ, Li Z, Zhao Y, Van Eck M \& Van Berkel TJ 2010 Plasma lipoproteins are required for both basal and stress-induced adrenal glucocorticoid synthesis and protection against endotoxemia in mice. American Journal of Physiology. Endocrinology and Metabolism 299 E1038-E1043. (doi:10.1152/ajpendo.00431.2010)

Huang CCJ, Shih MCM, Hsu NC, Chien Y \& Chung BC 2012 Fetal glucocorticoid synthesis is required for development of fetal adrenal medulla and hypothalamus feedback suppression. Endocrinology 153 4749-4756. (doi:10.1210/en.2012-1258)

Kakuta H, Tanaka M, Chambon P, Watanabe H, Iguchi T \& Sato T 2012 Involvement of gonadotropins in the induction of hypertrophy-hyperplasia in the interstitial tissues of ovaries in neonatally diethylstilbestrol-treated mice. Reproductive Toxicology 33 35-44. (doi:10.1016/ j.reprotox.2011.10.013)

Kaludjerovic J \& Ward WE 2012 The interplay between estrogen and fetal adrenal cortex. Journal of Nutrition and Metabolism 2012837901. (doi:10.1155/2012/837901)

Kitahara S, Umeda H, Yano M, Koga F, Sumi S, Moriguchi H, Hosoya Y, Honda M \& Yoshida K 1999 Effects of intravenous administration of high dose-diethylstilbestrol diphosphate on serum hormonal levels in patients with hormone-refractory prostate cancer. Endocrine Journal 46 659-664. (doi:10.1507/endocrj.46.659)

Korach KS \& McLachlan JA 1985 The role of the estrogen receptor in diethylstilbestrol toxicity. Archives of Toxicology. Supplement 8 33-42. (doi:10.1007/978-3-642-69928-3_4)

Kraemer FB 2007 Adrenal cholesterol utilization. Molecular and Cellular Endocrinology 265-266 42-45. (doi:10.1016/j.mce.2006.12.001)

Kuiper GG, Carlsson B, Grandien K, Enmark E, Häggblad J, Nilsson S \& Gustafsson JA 1997 Comparison of the ligand binding specificity and transcript tissue distribution of estrogen receptors $\alpha$ and $\beta$. Endocrinology 138 863-870. (doi:10.1210/endo.138.3.4979)

Kuzyk MA, Smith D, Yang J, Cross TJ, Jackson AM, Hardie DB, Anderson NL \& Borchers CH 2009 Multiple reaction monitoring-based, multiplexed, absolute quantitation of 45 proteins in human plasma. Molecular \& Cellular Proteomics 8 1860-1877. (doi:10.1074/mcp.M800540-MCP200)

Li Y, Okumura K, Nomura S, Maeda N, Miyasho T \& Yokota H 2011 Oxidatively damaged proteins in the early stage of testicular toxicities in male rats by orally administered with a synthetic oestrogen, diethylstilbestrol. Reproductive Toxicology 31 26-34. (doi:10.1016/ j.reprotox.2010.09.007)

Lowry OH, Rosebrough NJ, Farr AL \& Randall RJ 1951 Protein measurement with the folin phenol reagent. Journal of Biological Chemistry 193 265-275.

Maeda N, Tanaka E, Suzuki T, Okumura K, Nomura S, Miyasho T, Haeno S \& Yokota H 2013a Accurate determination of tissue steroid hormones, precursors and conjugates in adult male rat. Journal of Biochemistry 153 63-71. (doi:10.1093/jb/mvs121)

Maeda N, Okumura K, Tanaka E, Suzuki T, Miyasho T, Haeno S, Ueda H, Hoshi N \& Yokota H 2013b Down regulation of cytochrome P450scc as an an initial adverse effect of adult exposure to diethylstilbestrol on testicular steroidogenesis. Environmental Toxicology. (doi:10.1002/tox. 21875)

Martin OV, Shialis T, Lester JN, Scrimshaw MD, Boobis AR \& Voulvoulis N 2008 Testicular dysgenesis syndrome and the estrogen hypothesis: a quantitative meta-analysis. Environmental Health Perspectives 116 149-157. (doi:10.1289/ehp.10545)

Miller WL 2013 Steroid hormone synthesis in mitochondria. Molecular and Cellular Endocrinology 379 62-73. (doi:10.1016/j.mce.2013.04.014)

Miller WL \& Bose HS 2011 Early steps in steroidogenesis: intracellular cholesterol trafficking. Journal of Lipid Research 52 2111-2135. (doi:10.1194/jlr.R016675)

Newbold RR, Padilla-Banks E \& Jefferson WN 2006 Adverse effects of the model environmental estrogen diethylstilbestrol are transmitted to subsequent generations. Endocrinology 147(Suppl 6) S11-S17. (doi:10.1210/en.2005-1164)

Palmer JR, Herbst AL, Noller KL, Boggs DA, Troisi R, Titus-Ernstoff L, Hatch EE, Wise LA, Strohsnitter WC \& Hoover RN 2009 Urogenital abnormalities 
in men exposed to diethylstilbestrol in utero: a cohort study. Environmental Health 8 37. (doi:10.1186/1476-069X-8-37)

Sakaguchi K, Yokota H, Miyasho T, Maeda N, Nakamura K, Onaga T, Koiwa M, Matsuda K, Okamoto M, Hirayama K et al. 2013 Polymeric immunoglobulin receptor expression and local immunoglobulin A production in bovine sublingual, submandibular and parotid salivary glands. Veterinary Journal 197 291-296. (doi:10.1016/j.tvjl. 2012.12.030)

Schrager S \& Potter BE 2004 Diethylstilbestrol exposure. American Family Physician 69 2395-2400.

Shin JH, Kim TS, Kang IH, Kang TS, Moon HJ \& Han SY 2009 Effects of postnatal administration of diethylstilbestrol on puberty and thyroid function in male rats. Journal of Reproduction and Development $\mathbf{5 5}$ 461-466. (doi:10.1262/jrd.20169)

Stuber M \& Reemtsma T 2004 Evaluation of three calibration methods to compensate matrix effects in environmental analysis with LC-ESI-MS.
Analytical and Bioanalytical Chemistry 378 910-916. (doi:10.1007/ s00216-003-2442-8)

Unüvar T \& Büyükgebiz A 2012 Fetal and neonatal endocrine disruptors. Journal of Clinical Research in Pediatric Endocrinology 4 51-60. (doi:10.4274/Jcrpe.569)

Watson CS, Jeng YJ \& Guptarak J 2011 Endocrine disruption via estrogen receptors that participate in nongenomic signaling pathways. Journal of Steroid Biochemistry and Molecular Biology 127 44-50. (doi:10.1016/ j.jsbmb.2011.01.015

Wong EW \& Cheng CY 2011 Impacts of environmental toxicants on male reproductive dysfunction. Trends in Pharmacological Sciences 32 290-299. (doi:10.1016/j.tips.2011.01.001)

Zimmerman SA, Clevenger WR, Brimhall BB \& Bradshaw WS 1991 Diethylstilbestrol-induced perinatal lethality in the rat. II. Perturbation of parturition. Biology of Reproduction 44 583-589. (doi:10.1095/ biolreprod44.4.583)

Received in final form 12 February 2014

Accepted 25 February 2014

Accepted Preprint published online 27 February 2014
C 2014 Society for Endocrinology Printed in Great Britain
Published by Bioscientifica Ltd. 